\title{
Iron biomineralization by hyperthermophilic archaea
}

\author{
CHLOÉ TRUONG ${ }^{1}$, AURORE GORLAS ${ }^{2}$, FRANCOIS J \\ GUYOT $^{3}$ AND SYLVAIN BERNARD ${ }^{4}$
}

${ }^{1}$ CNRS - IMPMC

${ }^{2}$ Institut de Biologie Intégrative de la Cellule, Université Paris Saclay - CNRS

${ }^{3}$ CNRS-Institut de Minéralogie, de Physique des Matériaux et de Cosmochimie, Sorbonne Université - CNRS - MNHN

${ }^{4}$ Institut de Minéralogie, de Physique des Matériaux et de Cosmochimie, Sorbonne Université - CNRS - MNHN

Presenting Author: chloe.truong1@mnhn.fr

Sulfur-rich hydrothermal vents are ecosystems characterized by very extreme conditions of life. However numerous hyperthermophilic microorganisms have been isolated from there, mostly archaea whose predominant strains are the sulfurreducers Thermococcales. Therefore Thermococcales are deeply involved in hydrothermal vents sulfur cycle and still have a poorly understood geochemical impact.

We studied the mineralization of iron sulfides $\left(\mathrm{FeS}, \mathrm{Fe}_{3} \mathrm{~S}_{4}\right.$ greigite and $\mathrm{FeS}_{2}$ pyrite) and of iron phosphates related to the metabolic activity of Thermococcales, in order to better understand the response of these archaea to a highly mineralizing medium. We have coupled mineralogical methods (X-Ray Diffraction in anoxic conditions, Scanning Electron Microscopy and Energy Dispersive X-Ray Analysis) with gas content measurements and growth monitoring (cell couting and ATP measurements). These multi-scale analyzes were used to feed a thermo-kinetic model (Chess code) of the mineralization induced by Thermococcales in these extreme hydrothermal environments.

The metabolic activity of Thermococcales leads to an oxidation sequence of the FeS and iron(III) phosphates initially produced, coupled to a progressive reduction of electron acceptors $\mathrm{S}(0)$ and disulfide. Significant amounts of greigite nanocrystals are formed by Thermococcales at $85^{\circ} \mathrm{C}$ from a precursor amorphous iron (III) phosphates [1]. Thermococcales are also able to rapidly induce formation of abundant quantities of pyrite at $85^{\circ} \mathrm{C}$ when $\mathrm{S}(0)$ is directly available as vesicles either intracellularly or at the cell surfaces [2]. The formation of greigite and pyrite, destroying many cells and thus inducing the release of bioavailable organic nutrients and phosphates, allow the survival and growth of a non-mineralized Thermococcales cell fraction as detected by DNA sequencing and ATP measurements. This suggests that biologically induced ironsulfide mineralization is involved in an adaptive strategy at the population level, employed by Thermococcales to survive in strongly mineralizing high-temperature hydrothermal environments.

[1] Gorlas, Jacquemot, Guigner, Gill, Forterre, Guyot (2018), PLoS ONE 13(8)

[2] Gorlas, Marguet, Gill, Geslin, Guigner, Guyot, Forterre (2015), Biochimie 118, 356-364. 